Perspective Article

\title{
Zein impart hydrophobic and antimicrobial properties to cotton textiles
}

\author{
José Gonçalves, Natália Torres, Sónia Silva, Filipa Gonçalves, Jennifer Noro, Artur Cavaco-Paulo, \\ Artur Ribeiro*, Carla Silva* \\ Centre of Biological Engineering, University of Minho, Campus de Gualtar, 4710-057 Braga, Portugal
}

\section{A R T I C L E I N F O}

\section{Keywords:}

Zein

Hydrophobicity

Functional textiles

Antimicrobial activity

Protein coating

\begin{abstract}
A B S T R A C T
In this work, zein, a by-product of the agricultural industry of corn, was used to impart hydrophobicity and antimicrobial activity to textiles. The cotton textiles were functionalized with zein in two different forms, free or as particles. The optimized coating conditions which rendered the highest hydrophobic character to the textiles were found to be $50 \mathrm{~g} / \mathrm{L}$ zein in the free form prepared with $70 \%$ ethanol. To enhance the antimicrobial activity of the coated textiles, ellagic acid was encapsulated into the zein particles. These presented stable diameters, between 300 and $450 \mathrm{~nm}$, and positive surface charge revealing high encapsulation efficiency. After textiles coating, the controlled release of ellagic acid was tested against different mimetic biologic solutions. The release profile was dependent on the ethanol concentration, on the sweat solution $\mathrm{pH}$ and on the external media used during dialysis. The functionalized textiles revealed differentiated antimicrobial activity against Escherichia coli (Gram-negative) and Staphylococcus aureus (Gram-positive). For E. coli the activity was mainly related with the action of zein while for $S$. aureus a combined effect between the protein and the ellagic acid was observed. The results herein presented pave the way for the development of new zein-based products for a wide range of applications.
\end{abstract}

\section{Introduction}

The advancement of the Textile Industry has been leading to the development of new technologies aiming to add specific functions and properties to textiles. These new technologies are focused on textile coloration improvement, digital printing and smart and functional textiles development [1,2].

The use of biomaterials and nanotechnologies are strategical innovative options to produce advanced added value multifunctional textile materials through their surface modification [3,4]. Hydrophobicity is one of the most desired properties on industrial applications and for this reason several strategies have been undertaken to develop hydrophobic and super hydrophobic textiles. Hydrophobic surfaces have less surface energy, which reduces the bacterial capacity to adhere and proliferate in the materials $[5,6]$. For example, the hydrophobic functionalization of cotton-based textiles has been achieved through a non-fluorinated sol-gel method by crystalline suspension of titanium oxide. The results referred a marked hydrophobic behavior of functionalized cotton textiles preserving the hand feeling of the treated textiles, i.e. softness and smoothness [5]. In other study, textile surfaces were coated via layer-by-layer deposition of poly-L-lysine and carnauba wax particles. The combination of multiscale roughness and low surface energy of wax colloids resulted in long-lasting hydrophobicity on cotton surface already after two bilayers. The results showed the potential of the use of natural materials in textiles modification [7]. Also, superhydrophobic behavior (water contact angle $>150^{\circ}$ ) has been studied in order to develop superhydrophobic surfaces, which may be applied to control protein adsorption, cell interaction and bacterial growthas well as drug delivery systems $[8,9]$. Despite all the benefits described for the hydrophobic surfaces, their production is still based on the use of several hazardous chemicals requiring high-energy methods [10,11].

Textile materials are susceptible to degradation by microbial action which can be manifested in several ways, being the most common and least burdensome the formation of unpleasant odors [12]. Moreover, it can also lead to the degradation of their mechanical properties, decolorization and potentiate the appearance of dermal infections and allergic reactions in the textile users [13]. Textiles imparting antimicrobial properties must fulfill standard specifications which have been provided by the development of new coating technologies, replacing the traditional methods, ensuring that the properties and the quality of the final products are maintained [14]. Antimicrobial cotton textiles were developed by using a formulation of butanetetracarboxylic acid (BTCA) and chitosan. The results showed that after 10 washes the textiles entailed antimicrobial activity for bacteria and yeast, and

\footnotetext{
* Corresponding authors.

E-mail address: carla.silva@ceb.uminho.pt (C. Silva).
} 
maintained their physical properties [15]. Other approach for cotton textiles antimicrobial functionalization was also tested. Drug-loaded microspheres of bovine serum albumin (BSA) and casein were developed, by a fast sonochemical method, and applied onto cotton surfaces. The results showed that protein treated textiles may be applied as antimicrobial agents [16].

Together with coating functionalization, the application of nanoparticles to impart hydrophobicity and antimicrobial properties to the textiles has been explored. The nanoparticles present higher specificity and the functionalization of the textiles can be achieved by several techniques like sol-gel and layer-by-layer deposition $[17,18]$. However, despite the great potential of these systems, the textiles functionalization using protein complexes is still poorly explored [19]. Nevertheless, in a recent study antimicrobial cotton wound dressings were developed through coating with $\mathrm{pH}$-responsive human serum albumin/silk fibroin nanocapsules loaded with eugenol. The coated textiles inhibit Staphylococcus aureus and Escherichia coli growth [20]. Also, silver-based materials, due to their recognized antimicrobial activity, have been explored for textiles functionalization. A study regarding its application as wound dressing referred it as an effective alternative to antibiotics in wound infection management, working as a barrier to microorganisms. Moreover, the application of silver-based nanomaterials coupled with biopolymers for wound healing, showed positive outcomes in in vivo studies and offer an opportunity to overcome some industry drawbacks [21].

The intrinsic properties of hydrophobic proteins, like zein, make them potential agents for the functionalization of textiles to impart specific functions, namely hydrophobicity and antimicrobial activity. This protein has already demonstrated, by combining zein micro- and nanofibers, potentiality to produce functionalized cotton textiles for air filtration [22].

In this work, we choose zein to produce hydrophobic and antimicrobial textiles through an eco-friendly and economic approach. Zein is a prolamine obtained from corn gluten flour through solvent extraction methods and is rich in glutamic acid, leucine, proline and alanine [23,24]. Its properties such as biodegradability, biocompatibility, abundance, hydrophobicity and its ability to form films and fibers, make this protein a promising biopolymer for several applications [23], [25,26]. Zein has inherent hydrophobicity due to the high proportions of non-polar amino acid residues (more than $50 \%$ of total amino acid content), exhibiting a helical structure, composed of nine homologous anti-parallel repetition units, stabilized by hydrogen bonds [24,27]. The amphiphilic character of zein governs the formation of reversible macromolecular micelles, when this protein is in aqueous solutions with different polarity [28].

Although this protein is not used for human consumption, due to its negative nitrogen balance and low water solubility, it can be easily applied in the development of several applications [26,29]. Zein's transformation into films can be obtained by interactions with other materials by thermochemical cross-linking or by self-assembly. The result is a resistant, hydrophobic, biodegradable and safe material with antimicrobial properties [30,31]. Zein-based films, formed by self-assembly with solvent evaporation and electrostatic interactions, are referred as a potential material for food sector, as a biodegradable and eco-friendly coating agent which protects the contents from microbial degradation and enables the incorporation of antimicrobial compounds $[32,33]$. Despite that, its application on the textile field is still limited to the development of functional textiles based on zein nanofibers [34].

In this work, we explored the zein properties for the development of hydrophobic and antimicrobial functional textiles, by coating of textiles using two different approaches: zein in the free form or in the form of particles. To increment the antimicrobial properties of zein $[35,36]$, ellagic acid, a known antimicrobial agent [37,38], was encapsulated into the zein particles. To validate this technology, the textiles' hydrophobicity was evaluated by water drop absorption and contact angle. The coating was confirmed by scanning electron microscopy (SEM) and thermogravimetric analysis (TGA). The physio-chemical properties of the zein particles were evaluated by dynamic light scattering (DLS). The release of ellagic acid from the textiles coated with zein particles was analyzed using different mimetic biological solutions. The fastness to washing and friction and the air permeability of the functionalized textiles was evaluated according to standard procedures.

\section{Experimental}

\subsection{Materials}

As a matrix for the zein coating, a $100 \%$ bleached cotton textile composed of 36 warp $/ 35$ weft yarns with a density of $47.3 \mathrm{~g} / \mathrm{m}^{2}$ was used. Zein and ellagic acid, were both purchased from MerckSigma, Spain. The $\mathrm{DC}^{\mathrm{TM}}$ colorimetric kit was obtained from BioRad, Portugal. All other reagents were used as supplied.

\subsection{Characterization of functionalized cotton textiles with free zein}

\subsubsection{Textiles functionalization with free zein}

Prior to functionalization, the cotton textiles were washed with a solution of $0.1 \%$, Lutensol AT 25 , for $1 \mathrm{~h}$ at $50^{\circ} \mathrm{C}$, followed by rinsing with deionized water and dried in oven at $40^{\circ} \mathrm{C}$.

For the development of hydrophobic cotton, the textiles were coated with solutions of zein $(10,20$ and $50 \mathrm{~g} / \mathrm{L})$ prepared in different concentrations of ethanol $(70 \%, 80 \%$ and $90 \%)$. For this, the zein was added to the ethanol and kept under stirring for $10 \mathrm{~min}$ at $500 \mathrm{pm}$. The coating of the cotton samples with the free zein was performed by depletion, impregnation by dropwise addition and impregnation by padding. No chemical reaction between the cellulosic structure of cotton and zein was established being the textiles functionalization based on adhesion mechanisms.

\subsubsection{Water drop absorption test}

The functionalized samples and the respective controls were tested for their capacity to absorb water, using the water drop absorption technique. A drop of water from a fixed height was dropped on the textile and the time until total absorption was measured. Readings were taken in triplicate and at different spots of each sample. The results represent the mean of the measurements.

\subsubsection{Contact angle measurement}

The contact angle between water and the functionalized cotton textiles was measured using the Dataphysics Instruments OCA 20 equipment equipped with Sca 20 software. Parameters like the droplet volume $(2 \mu \mathrm{L})$ and the rate of droplet release $(1 \mu \mathrm{L} / \mathrm{s})$ were fixed. The image of the drop formed at the surface of the textiles was acquired through a high-speed camera. The contact angle was measured in 5 different locations of each sample.

\subsubsection{Thermogravimetric analysis (TGA)}

Thermogravimetric studies were conducted in a TGA 4000 (Perkin Elmer, Waltham, MA, USA) using a sample weight alumina crucible of $\pm 9 \mathrm{mg}$. The temperature calibration was performed by Curie temperatures of reference for Alumel, Nickel and Perkalloy at the same sweep rate as the sample. The sample analysis were taken from 25 to $800^{\circ} \mathrm{C}$ at $20^{\circ} \mathrm{C} / \mathrm{min}$ under a nitrogen atmosphere (Flow: $20 \mathrm{~mL} / \mathrm{min}$ ). The percentage of weight loss and its derivative were plotted against temperature and data were acquired in Piris software.

\subsubsection{Fourier-transform infrared spectroscopy (FTIR)}

Infrared spectra of the cotton samples were obtained using 45 scan cycles, between 400 and $4000 \mathrm{~cm}^{-1}$ with a resolution of $8 \mathrm{~cm}^{-1}$, in a Shimadzu FTIR spectrometer IRAffinity-1S. 


\subsubsection{Scanning electron microscopy (SEM)}

The coating of the cotton samples was characterized using a Phenom scanning electron microscope, Pro X (Phenom-World BV, Netherlands). The samples were added to aluminum pins with carbon electrically conductive tape (PELCO Tabs ${ }^{\mathrm{TM}}$ ) and coated with $2 \mathrm{~nm}$ gold (Au) to improve conductivity.

\subsubsection{Tensile strength}

Tensile strength tests were performed according to the method of ASTM D5035 strip using a Hounsfield dynamometer H100KS Model. The load range applied was $500 \mathrm{~N}$, with $2 \mathrm{~N}$ preload, $50 \mathrm{~mm}$ extension range, $100 \mathrm{~mm}$ length and $100 \mathrm{~mm} / \mathrm{min}$. The test pieces were with size of $20 \times 5 \mathrm{~cm}$, respecting the orientation of the fibers (web direction and weft direction). For each test, 10 specimens were tested, and the data were converted to stress (load/unit area) vs. strain (\% extension).

\subsubsection{Rubbing fastness}

The wet and dry friction fastness tests were performed following the ISO 105 - X12: 2016, using a Crockmeter equipment. Each sample was rubbed against a control tissue (cotton) for ten cycles. The assay was repeated for each sample three times. The results were evaluated through the greyscale on a light chamber (D65).

\subsubsection{Washing fastness}

The washing fastness test was performed according to the ISO 105C06: 2010. The assay was performed in a Rotawash machine using stainless steel containers with 50 stainless steel balls mixed with the samples. The washing was performed for $40 \mathrm{~min}$ at $50^{\circ} \mathrm{C}$, afterwards the samples were placed in an oven at $50^{\circ} \mathrm{C}$ for $2 \mathrm{~h}$ until completely dry. The results were evaluated by greyscale on a light chamber (D65).

\subsubsection{Air permeability}

The air permeability of the functionalized cotton samples was performed using the standard procedure NP EN ISO 9237. The samples with $20 \mathrm{~cm}^{2}$ were prepared and a vapor pressure $100 \mathrm{~Pa}$ was applied. All the tests were repeated 10 times for each sample.

\subsection{Characterization of functionalized cotton textiles with zein particles}

\subsubsection{Production of zein particles}

Prior to particles preparation, $10 \mathrm{~g} / \mathrm{L}$ zein solution was prepared in two ethanol concentrations (70 and $80 \%$ ). The particles were prepared by adding the zein solution $(10 \mathrm{~mL})$ to a defined volume of water $(10 \mathrm{~mL})$. The particles containing the antimicrobial agent were prepared by adding a solution of ellagic acid $(1 \mathrm{mg} / \mathrm{mL})$, prepared in ethanol (70 and $80 \%$ ), to a $10 \mathrm{~g} / \mathrm{L}$ zein solution, also prepared in ethanol (70 and $80 \%)$. To promote the formation of the particles and the encapsulation of the ellagic acid, the prepared solution containing zein and ellagic acid was added to water (zein:water ratio of 1:1).

\subsubsection{Evaluation of zein particles formation efficiency}

The efficiency of particles formation was measured by separating the free protein from the formed particles using $100 \mathrm{kDa}$ centrifugation Amicon tubes. The free protein was quantified by $\mathrm{DC}^{\mathrm{TM}}$ colorimetric method (detergent compatible). A calibration curve was performed with BSA standard solutions $(0.05 \mathrm{mg} / \mathrm{mL}-2 \mathrm{mg} / \mathrm{mL})$ and the absorbance of the samples was measured at $750 \mathrm{~nm}$.

\subsubsection{Efficiency of ellagic acid encapsulation}

The efficiency of ellagic acid encapsulation was evaluated by separation of the free compound using a PD-10, SephadexTM G-25 column. The quantification of the free ellagic acid was made by UV-Visible spectroscopy $(\lambda=370 \mathrm{~nm})$.

\subsubsection{Stability of zein particles}

The stability of the zein particles along storage was followed by the evaluation of the particles size, surface charge and polydispersion index (PDI), using the DLS - dynamic light scattering method (Zetasizer, Malvern Instruments, Nano-ZS). The physico-chemical stability of the particles was performed weekly up to 12 weeks of storage at $4{ }^{\circ} \mathrm{C}$.

\subsubsection{Textiles functionalization with zein particles}

Prior to functionalization, the cotton textiles were washed with a solution of $0.1 \%$, Lutensol AT 25 , for $1 \mathrm{~h}$ at $50^{\circ} \mathrm{C}$, followed by rinsing with deionized water and dried in oven at $40^{\circ} \mathrm{C}$. To develop antimicrobial surfaces, the cotton textiles were coated with zein particles $(5 \mathrm{mg} / \mathrm{mL})$ by padding. No chemical reaction between the cellulosic structure of cotton and zein was established being the textiles functionalization based on adhesion mechanisms.

\subsubsection{Ellagic acid controlled release}

The release of ellagic acid from the zein particles was evaluated using dialysis membranes of $1 \mathrm{kDa}$ cut-off. The functionalized textiles $(1 * 1 \mathrm{~cm})$ were placed inside dialysis membranes against conditions of internal/external media: i) alkaline sweat solution ( $\mathrm{pH} 8) /$ water; ii) acidic sweat solution ( $\mathrm{pH}$ 5)/water; iii) alkaline sweat solution ( $\mathrm{pH} 8)$ / micellar solution; iv) acidic sweat solution ( $\mathrm{pH}$ 5)/micellar solution and v) water/water. During release studies the dialysis membranes were placed at $37{ }^{\circ} \mathrm{C}$ under $60 \mathrm{rpm}$. The absorbance of the external releasing solutions was measured by UV/Vis spectroscopy $(\lambda=370 \mathrm{~nm})$ at different time-points $(1 \mathrm{~h} ; 2 \mathrm{~h} ; 4 \mathrm{~h} ; 6 \mathrm{~h} ; 8 \mathrm{~h} ; 24 \mathrm{~h}, 48 \mathrm{~h}$ and $72 \mathrm{~h})$.

The alkaline and the acidic sweat solution were prepared according to the procedures described in NP EN ISO 105 E04: 1997 and the micellar solution was prepared with sodium lauryl sulfate $(16 \mathrm{mM})$.

\subsubsection{Antimicrobial activity of functionalized textiles}

The antimicrobial activity of zein-functionalized cotton textiles was evaluated against Gram-positive, Staphylococcus aureus strain (S. aureus; ATCC 6538) and Gram-negative, Escherichia coli strain (E. coli; CECT 434), using the quantitative method based on the AATCC 1002004 standard. The textile samples were previously sterilized under UV for 30 min. Each strain was incubated with TSB inoculum (Triptych broth of soybean) for $24 \mathrm{~h}$ at $37^{\circ} \mathrm{C}$. The bacterial concentration was adjusted with TSB to $1 \times 10^{6}$ cells $/ \mathrm{ml}$. Then $4 \mathrm{~mL}$ of diluted inoculum was placed in contact with each square textile $(0.5 \times 0.5 \mathrm{~cm})$ and incubated for $24 \mathrm{~h}$ at $37^{\circ} \mathrm{C}$. Afterwards, $10 \mathrm{~mL}$ of $0.1 \mathrm{M}$ PBS was added to the samples and homogenized in the vortex. The number of living bacteria was determined by serial counting of the dilution plates. TSA agar plates (Tryptic Soy Agar) were incubated for $24 \mathrm{~h}$ at $37^{\circ} \mathrm{C}$ and the total of CFUs was quantified. All tests were performed in duplicate and repeated three times.

\subsubsection{Thermogravimetric analysis (TGA)}

Thermogravimetric studies were conducted as described in 2.2.4.

\subsubsection{Fourier-transform infrared spectroscopy (FTIR)}

Infrared spectra of the cotton samples were performed as described in 2.2.5.

\subsubsection{Scanning electron microscopy (SEM)}

The coating of the cotton samples was characterized as described in 2.2.6.

\subsubsection{Rubbing fastness}

The wet and dry friction fastness tests were performed following the ISO 105 - X12: 2016, as described in 2.2.8.

\subsubsection{Washing fastness}

The washing fastness test was performed according to the ISO 105C06: 2010 as described in 2.2.9. 


\subsubsection{Air permeability}

The air permeability of the functionalized cotton samples was performed as described in 2.2.10.

\subsection{Statistical analysis}

The data is presented as average standard deviation (SD), $n=3$. Statistical comparisons were performed by one-way ANOVA with GraphPad Prism 8.0 software (La Jolla, CA, USA). Tukey's post-hoc test was used to compare all the results between them, and a Dunnet's test was used to compare the results with a specific control. A $p$-value $<.05$ was considered to be statistically significant.

\section{Results and discussion}

\subsection{Cotton textiles hydrophobization}

\subsubsection{Water absorption and contact angle}

In this work, we used an eco-friendly approach, based on interaction/adhesion forces, to functionalize cotton textiles with zein. After functionalization, the degree of hydrophobization was evaluated by measuring the time of water drop absorption and the contact angle. The results of time of water absorption (Fig. 1) reveal that all the tested conditions impart hydrophobicity to the cotton textiles. The degree of hydrophobization was dependent on the zein concentration and application method, with the best results obtained for $50 \mathrm{~g} / \mathrm{L}$ of zein, prepared with 70\% ethanol, applied on cotton by padding. The results also revealed that the ethanol also played an important role on the final hydrophobization of cotton. It was observed that as the percentage of ethanol increased, the time of water drop absorption decreased. This is mainly related with the low affinity of the protein to water. As the ethanol content of solvent increased from $70 \%$ to $90 \%$, the aggregation of zein molecules decreased [28]. The aggregation behavior of zein at $70 \%$ of ethanol leads to a greater deposition of the protein at the cotton textile surface, resulting in a hydrophobic thicker film. The variation of the results (apparent increase of the time of water drop absorption with the increase of alcohol content) observed for the samples functionalized with $10 \mathrm{~g} / \mathrm{L}$ and $20 \mathrm{~g} / \mathrm{L}$ of zein applied on cotton by padding, are most likely related with the pattern of zein deposition, which was not uniform for these samples (data not shown). These samples presented areas with zein strongly deposited and areas with a lower deposition of the protein, which might explain the variations observed in Fig. 1. As control it were used only washed cotton textiles which absorbed immediately the water drop (data not shown). Fig. 2 reveal the effect of the protein deposition, after functionalization by padding. The samples coated with $50 \mathrm{~g} / \mathrm{L}$ zein prepared with the lowest ethanol concentration (70\%) (Fig. 2B) present the highest degree of modification highlighted

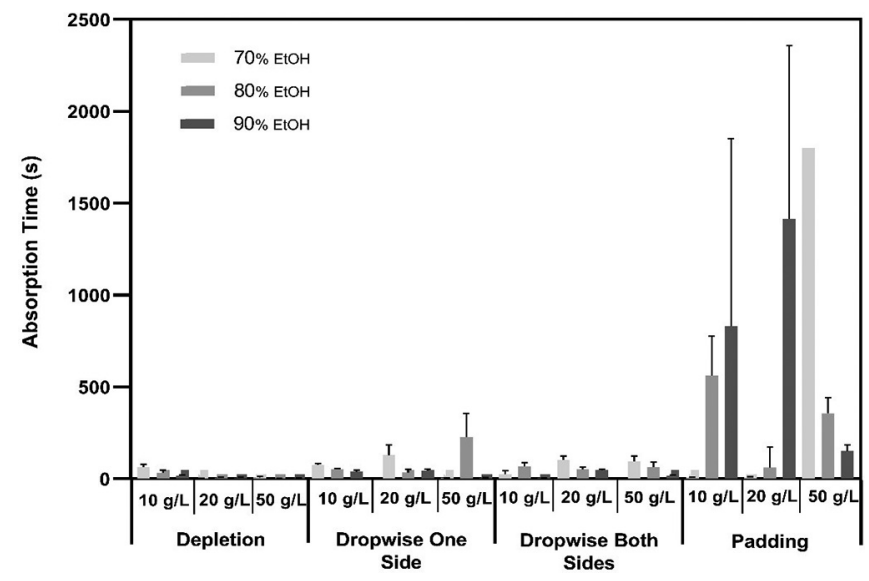

Fig. 1. Time of water drop absorption of zein-functionalized cotton textiles. by the yellow coloration.

The textiles' hydrophobicity was also confirmed by the analysis of the contact angle between the water and the functionalized surfaces (Fig. 3 and Table SI). All the samples presented hydrophobic character at time zero (water contact angle equal or greater than $90^{\circ}$ ) [39]. However, some differences were observed between the samples for this time, with an increase on the initial contact angle with the increase of the ethanol content. These differences could be related with the amount of protein adhered to the textile, the uniformity of the deposition pattern and with potential structures formed by the zein when dissolved in higher ethanol concentrations. Yet, after $180 \mathrm{~s}$ of measurement, only the samples functionalized with $50 \mathrm{~g} / \mathrm{L}$ of zein prepared with $70 \%$ ethanol and applied by padding, revealed a high contact angle (Fig. 3). Other works involving the study of the hydrophobicity of zein-based materials already refer to contact angles of this degree of magnitude [40,41].

Due to the low hydrophobic character of the samples functionalized with zein concentrations lower than $50 \mathrm{~g} / \mathrm{L}$, and of the sample functionalized with $50 \mathrm{~g} / \mathrm{L}$ zein/90\% ethanol/padding (Fig. 1 and Fig. 3), only the samples functionalized with $50 \mathrm{~g} / \mathrm{L}$ of zein prepared with $70 \%$ or $80 \%$ ethanol applied by padding, were considered for further characterization.

\subsubsection{Thermogravimetric analysis (TGA)}

The thermogravimetric behavior of functionalized cotton samples was evaluated and presented in terms of mass loss (Table SII and Fig. SI). The textiles coated with zein displayed a thermogravimetric profile similar to the control (washed cotton sample), however presenting different weight losses at around $400{ }^{\circ} \mathrm{C}$ and $800{ }^{\circ} \mathrm{C}$. While the control sample loses almost all the weight around $400^{\circ} \mathrm{C}$, the functionalized textiles still maintain $30 \%$ of the original weight. At $800{ }^{\circ} \mathrm{C}$ the samples revealed a residual amount of the initial material, which was higher for the samples functionalized with the zein protein. The differences in the values of mass loss and residual weight were directly related to the presence of the zein at the textiles' surface.

\subsubsection{FTIR}

The functionalization of the cotton textiles with zein was analyzed by FTIR (Fig. 4). The spectra of the control textile showed the presence of the characteristic cotton peaks, $\mathrm{O}-\mathrm{H}$ vibration at $3310 \mathrm{~cm}^{-1}, \mathrm{C}-\mathrm{H}$ vibration at $2916 \mathrm{~cm}^{-1}$ and C-O-C vibration at $1034 \mathrm{~cm}^{-1}$ [42]. The functionalized samples revealed identical profiles, except with the appearance of two peaks corresponding to the Amide $I$ and Amide II at $\approx$ $1656 \mathrm{~cm}^{-1}$ ( $\mathrm{C}=\mathrm{O}$ stretching) and at $\approx 1543 \mathrm{~cm}^{-1}$ ( $\mathrm{C}-\mathrm{N}$ stretching and $\mathrm{N}-\mathrm{H}$ bending) [42,43], respectively. These peaks confirm the presence of zein at the textiles' surface.

\subsubsection{SEM}

The surface morphology of the cotton samples was evaluated using scanning electronic microscopy (SEM). The non-functionalized cotton textiles (control) presented a smooth and uniform surface (Fig. 5A), while the textiles functionalized with zein showed a less homogeneous and rougher morphology, indicating the presence of the protein at the fiber's surface (Fig. 5B and C). The SEM images also suggest that zein tends to create a thin layer, filling the empty spaces between the fibers, leading to a more cohesive textile structure. This might impart a hydrophobic character to the coated textiles.

\subsubsection{Tensile strength}

The mechanical properties (breaking strength and stretching) were evaluated and the data revealed a different behavior between the warp and the weft yarns. When a force is exerted along with the warp, the cohesive forces allow the textile to resist to higher mechanical stress. The weft presents higher elasticity, resulting in greater elongation and lower breaking strength [44]. From the results obtained (Fig. 6), it seems that the coating with zein ([50 g/L]; 70\% ethanol) contributed to 

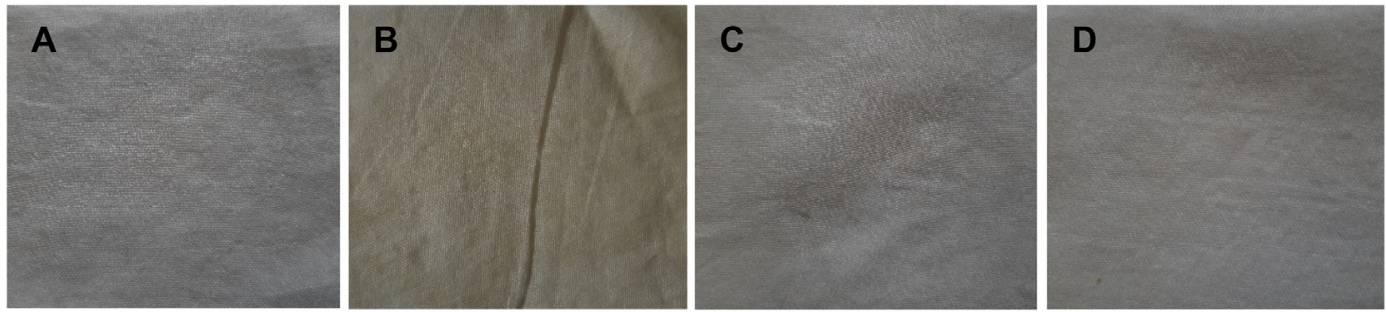

Fig. 2. Photographs of coated cotton textiles: control A), $50 \mathrm{~g} / \mathrm{L}$ zein prepared in $70 \%$ EtOH B), $50 \mathrm{~g} / \mathrm{L}$ zein prepared in $80 \%$ EtOH C) and $50 \mathrm{~g} / \mathrm{L}$ zein prepared in 90\% EtOH D).

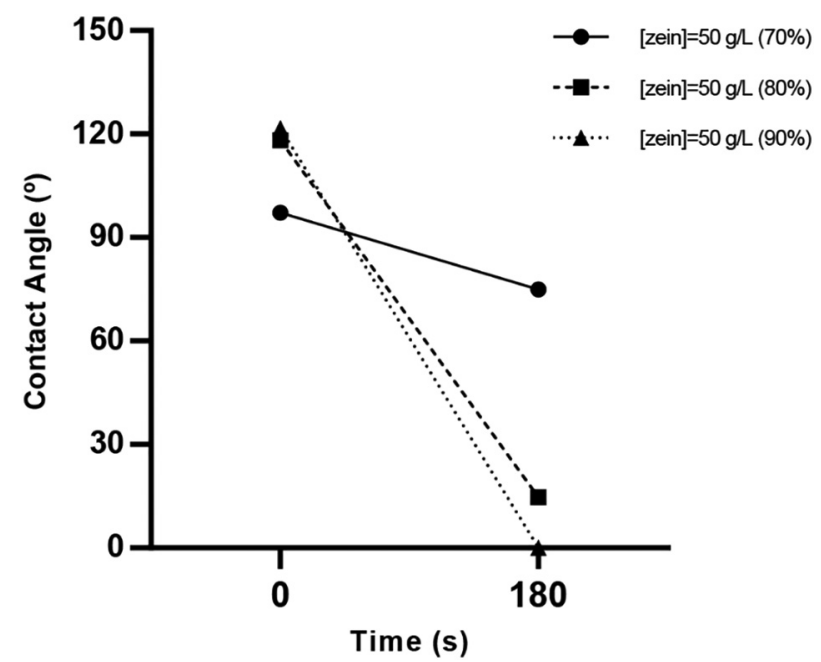

Fig. 3. Water drop contact angle of the functionalized surfaces measured between $0 \mathrm{~s}$ and $180 \mathrm{~s}$.

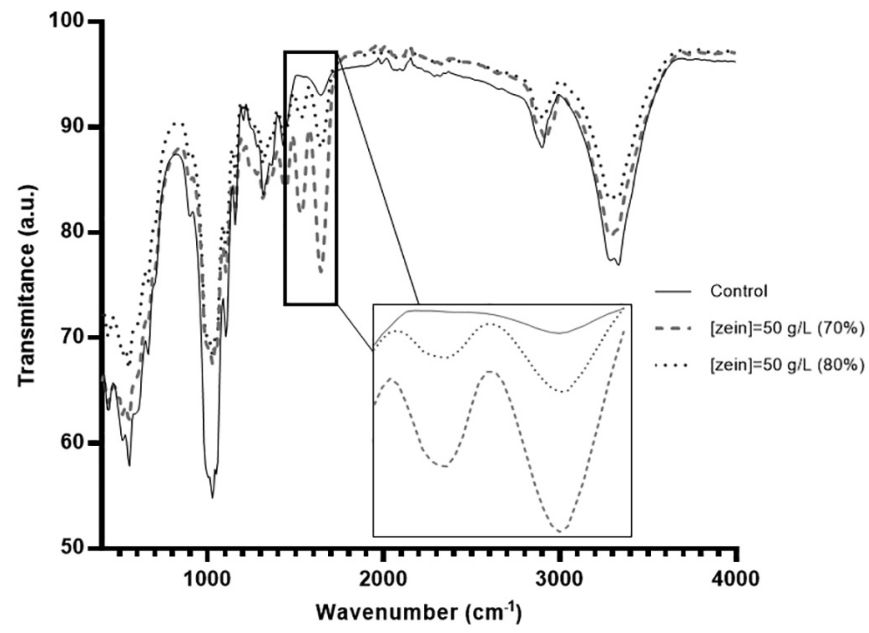

Fig. 4. FTIR spectra of cotton textiles functionalized with [zein] $=50 \mathrm{~g} / \mathrm{L}$ in ethanol concentrations of $70 \%$ and $80 \%$. The control corresponds to the sample cotton textile without zein.

a better mechanical performance of the warp, in terms of breaking strength, comparing with the control and the samples coated with zein ([50 g/L]; 80\% ethanol). The improvement of the breaking strength of the warp was accompanied by a decrease of the elongation resulting from the stronger cohesive forces between the fibers. The fiber shrinkage and the increase in fabric density could be responsible for this improvement.

The lower mechanical performance of the weft yarns after functionalization, especially of samples coated with $[50 \mathrm{~g} / \mathrm{L}] ; 70 \%$ ethanol, might be attributed to the higher inter-fibers friction resistance resulting from zein deposition, which hindered the elongation behavior of the yarns, decreasing therefore their breaking strength. The interyarn and interfiber spaces were filled with the zein coating which rigidified the spacer fabric and decreased its elasticity. Moreover, the weft yarns, generally less resistant to mechanical stress and with less density than warp yarns, seem to be more easily disturbed by the coating effects revealing lower mechanical performance.

\subsection{Zein particles}

Cotton textiles were functionalized by padding with zein particles encapsulating ellagic acid. To evaluate the antimicrobial activity of the ellagic acid, samples functionalized with empty zein particles were used as controls. The composition of the final zein particles was $5 \mathrm{mg} / \mathrm{mL}$ zein containing $0.5 \mathrm{mg} / \mathrm{mL}$ of ellagic acid, in ethanol (35 or $40 \%$ ).

\subsubsection{Characterization and stability of zein nanoparticles}

The physio-chemical characterization reveals particles with size diameter between 380 and $450 \mathrm{~nm}$ with a positive surface charge (Fig. 7). One can observe that the percentage of ethanol during preparation seems to influence greatly the size of the particles, leading to higher diameters when prepared with $80 \%$ ethanol (final concentration: 40\%) (Fig. 7A). This makes possible to control the characteristics of the particles depending on the final application. However, no influence of ethanol concentration was observed for the surface charge (Fig. 7B). It is noteworthy that the positive charge of the particles might improve the adhesion of the particles to the slight negative cotton surface [45]. The zein particles remain stable along time regarding size, however surface charge variations were detected during storage. Moreover, its encapsulation efficiency, showed at 3.2.2, reveals that this particle system is appropriate to incorporate active compounds.

\subsubsection{Encapsulation efficiency}

The efficiency of encapsulation was evaluated spectrophotometrically at $370 \mathrm{~nm}$. As for the size of the particles, the concentration of ethanol during preparation also influenced the amount of ellagic acid encapsulated. The encapsulation of ellagic acid was $94.79 \%$ and $74.79 \%$, for zein particles with a final ethanol concentration of $35 \%$ and $40 \%$, respectively.

\subsubsection{Controlled release of ellagic acid from functionalized textiles}

The potential of zein-based particles for the controlled release of active compounds was tested (Fig. 8). The controlled release of ellagic acid from the zein particles at the textiles' surface was studied using different internal medium (acid and basic sweat solution, and water) and two external media (water and micellar solution $\mathrm{pH}$ 5.5). The conditioning media was chosen to mimic the release of the compound during perspiration, and the micellar solution was used to simulate or mimic, not only the $\mathrm{pH}$ value of the skin [46], but also the membranous/aqueous environment encountered in the interlamellar regions of the stratum corneum, that constitutes one of the most important barriers for compounds permeation [47]. Although all the tested conditions induced the release of ellagic acid in a controlled manner, the final 

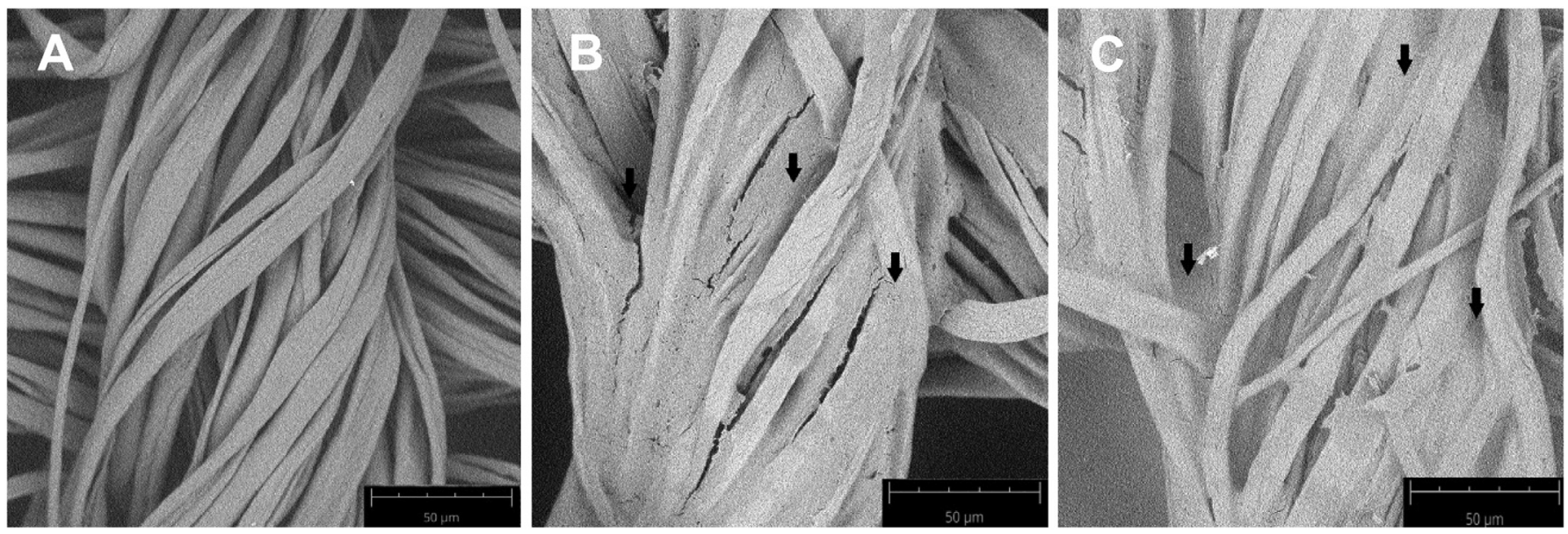

Fig. 5. SEM images with an amplification magnitude of $1150 \times$, of control cotton A), functionalized textiles with [zein] $=50 \mathrm{~g} / \mathrm{L}(70 \% \mathrm{EtOH}) \mathrm{B})$ and with [zein] $=50 \mathrm{~g} / \mathrm{L}(80 \% \mathrm{EtOH}) \mathrm{C})$. The arrows highlight the coating with zein in the fibers and interfiber spaces.

concentration of the compound, at the end of $72 \mathrm{~h}$, was lower than $90 \%$ of the encapsulated concentration.

The release profile of ellagic acid was dependent on the ethanol concentration used during particles preparation, on the sweat solution $\mathrm{pH}$ and on the external media used during dialysis (water $v s$ micellar solution). Zein particles containing $35 \%$ ethanol released approximately 2 -fold more ellagic acid than particles containing $40 \%$ ethanol.

The internal alkaline sweat solution induced a higher release of the compound, when compared with the acid one. Zein's secondary structure is strongly affected by $\mathrm{pH}$, above 6.8 all protein adopts alpha helix rearrangement resulting in higher compound release [48]. The micellar solution revealed to be a better external medium for ellagic acid release than water, which might be related with zein's high hydrophobicity, that enhances a protein structure rearrangement leading to a decrease of the release kinetics, when particles are in contact with water [49].

\subsubsection{Thermogravimetric analysis}

The thermogravimetric analysis of functionalized samples was undertaken to infer the influence of the zein particles coating on the thermal stability of the cotton textiles.

Fig. SII and Table SIII show the thermogravimetric analysis of the cotton samples coated with zein particles (with and without ellagic acid). The textiles with zein displayed a thermogravimetric profile similar to the control (washed cotton sample). However, at $800{ }^{\circ} \mathrm{C}$, the samples coated with the zein particles (with and without ellagic acid) presented higher residual weight. Comparing with the previous results obtained for the textiles coated with free zein $(50 \mathrm{~g} / \mathrm{L})$, it was observed a higher mass loss at $400{ }^{\circ} \mathrm{C}$ and a lower residual mass, related with the amount of zein applied $(5 \mathrm{~g} / \mathrm{L})$.

\subsubsection{SEM}

The surface morphology of the cotton samples functionalized with zein particles was evaluated using scanning electronic microscopy (SEM) (Fig. 9). The non-functionalized cotton textiles (control) presented a smooth and uniform surface (Fig. 9A), while the functionalized textiles showed the presence of particle aggregates and the formation of a zein film, pointed out by arrows (Fig. 9B-D). The presence of the ellagic acid, encapsulated in the zein particles, did not affected the particles' deposition pattern (Fig. 9C - 35\%EtOH, and Fig. 9D - 40\%EtOH), since no significant differences were observed when comparing with the cotton functionalized with particles without ellagic acid (Fig. 9B).

\subsubsection{Antimicrobial activity}

The quantitative method was chosen to explore the antimicrobial activity of the coated textiles since, due to diffusion constrains, no defined halo was possible to obtain when the qualitative method was tried. According to the requirements of the standard procedures, antibacterial activities of the front and back sides of the studied materials
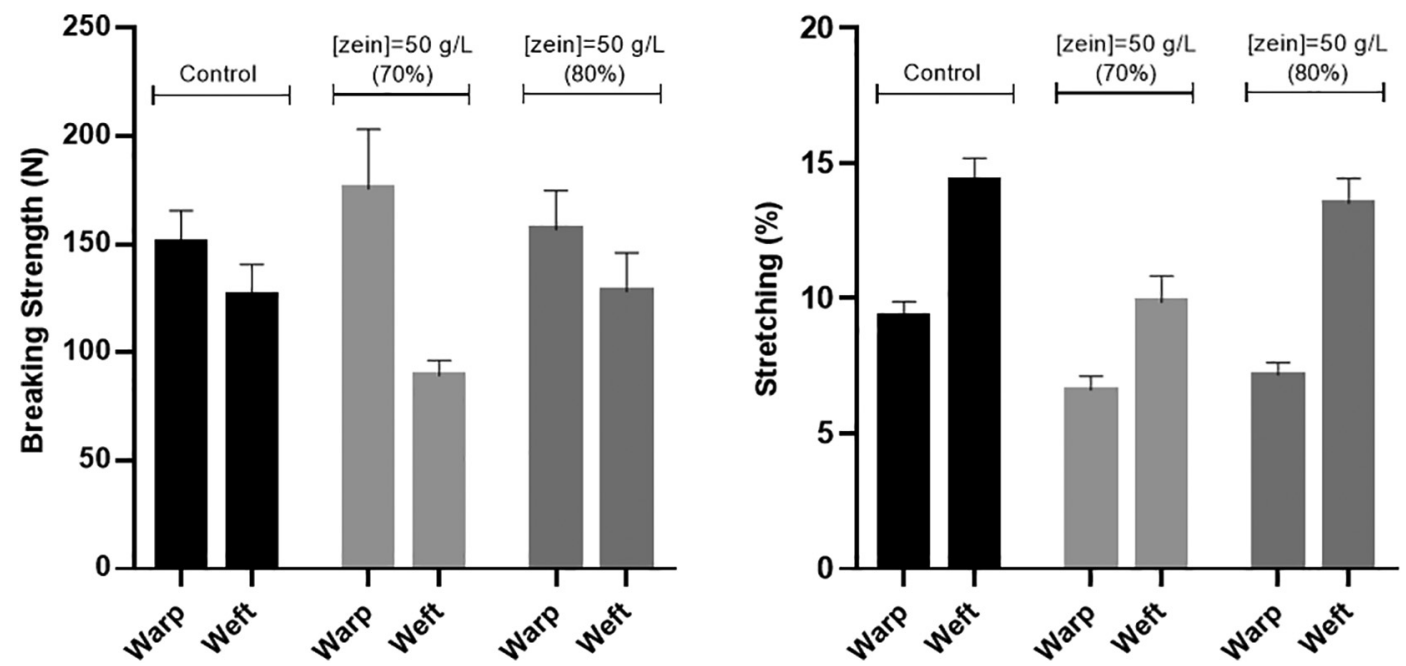

Fig. 6. Breaking strength and stretching of functionalized cotton textiles by padding with zein $[50 \mathrm{~g} / \mathrm{L}]$ at $70 \%$ and $80 \%$ ethanol. The control corresponds to the cotton textile without protein functionalization. 
(a)
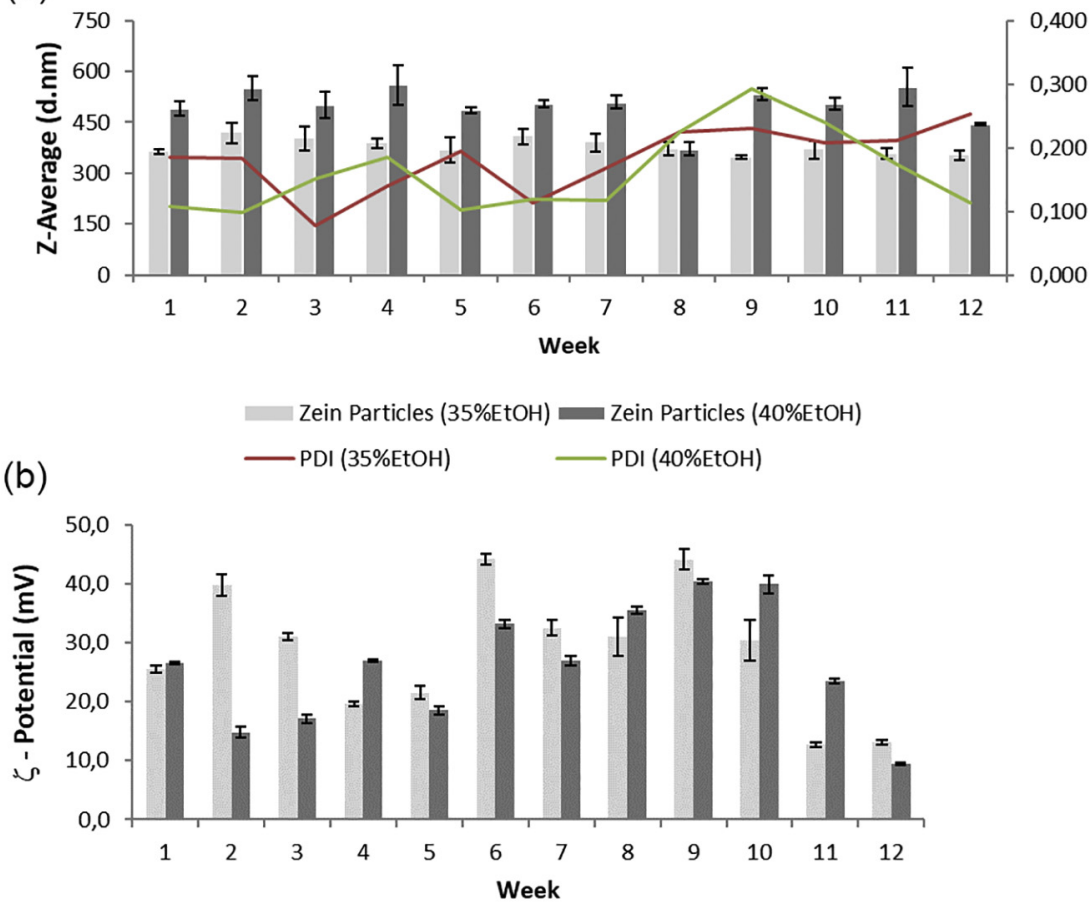

Zein Particles $(70 \%$ EtOH) $\quad$ Zein Particles $(80 \%$ EtOH $)$

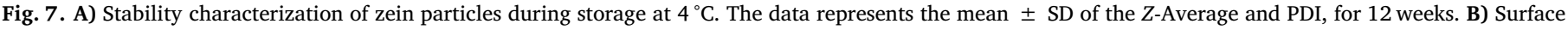
charge ( $\zeta$-Potential $(\mathrm{mV})$ ) of zein particles. The data represents the mean \pm SD for 12 weeks.

should to be determined. However only marginal differences between the growth on both sides of coated fabrics were observed by quantitative method against Gram-positive ( $S$. aureus) and Gram-negative (E.coli).

The ability of ellagic acid to confer antimicrobial activity to cotton textiles when encapsulated in zein particles was thus evaluated by using the quantitative method (Fig. 10 and Fig. SIII). For this, the activity of samples functionalized with zein particles with and without ellagic acid was tested in E. coli (Gram-negative) and in S. aureus (Gram-positive). Analyzing the results (Fig. 10A and B), there was an antimicrobial effect of the textiles functionalized with zein particles containing ellagic acid against $E$. coli and $S$. aureus. Regarding the results obtained for $E$. coli, we can also conclude that the antimicrobial effect was mainly attributed to the presence of zein, which, due to its intrinsic characteristics, impart antimicrobial activity to the textiles. In this study we used yellow zein, rich in carotenoids particularly lutein and zeaxanthin [50], which are described to have some antimicrobial activity [51]. Although their direct antibacterial mechanism is still not completely understood, it can be related with the ability of lutein and zeaxanthin to easily insert into biological membranes and to increase the rigidity of lipidic bilayers [52]. Recent studies also reported the ability of lutein to interact with four proteins - LasI, LasR, RhlI and RhlR, involved in the quorum sensing mechanism during biofilm formation [51].

The effect against $S$. aureus was considerably lower, however the presence of ellagic acid in the particles, prepared with $35 \%$ of ethanol, showed statistical significance most likely related with its release from the particles. Ellagic acid has been described as presenting antimicrobial activity against $H$. pylori [53] and $S$. paratyphi [54]. Its antimicrobial activity is attribute to the effect on the membrane permeability and cellular metabolism [54]. An increase on the effect of ellagic acid could be attained by incubating the bacterial inoculum for longer time with the functionalized textiles, allowing a higher release of ellagic
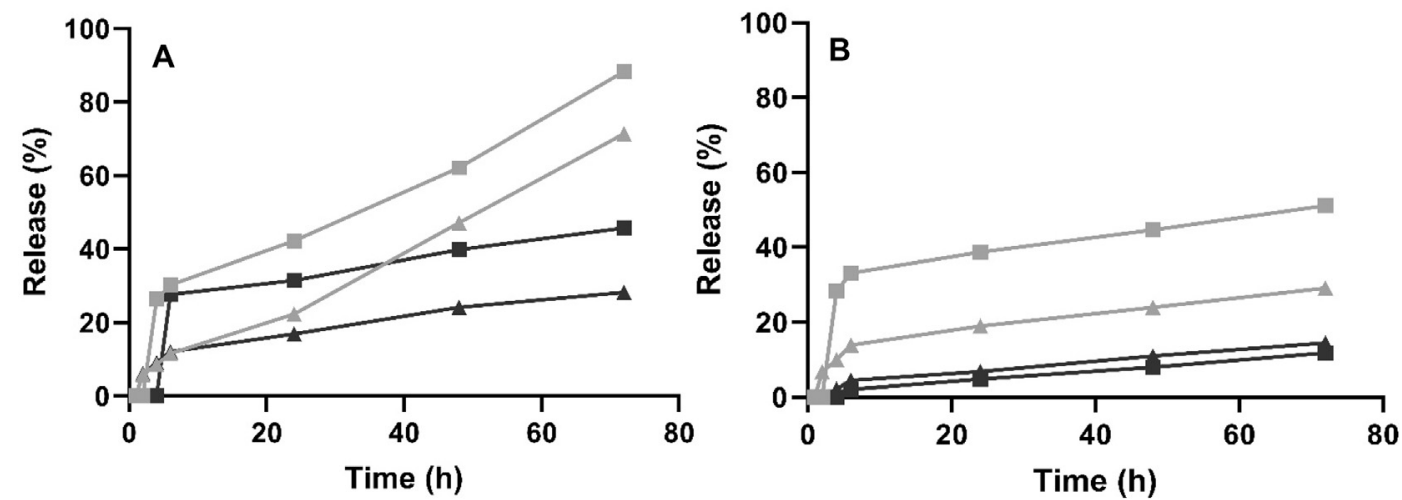

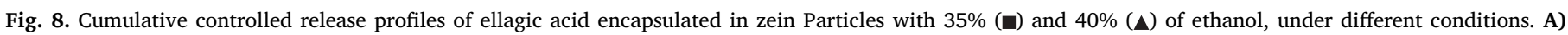

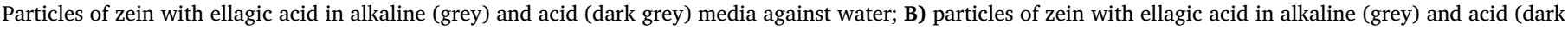
grey) media against micellar solution. 

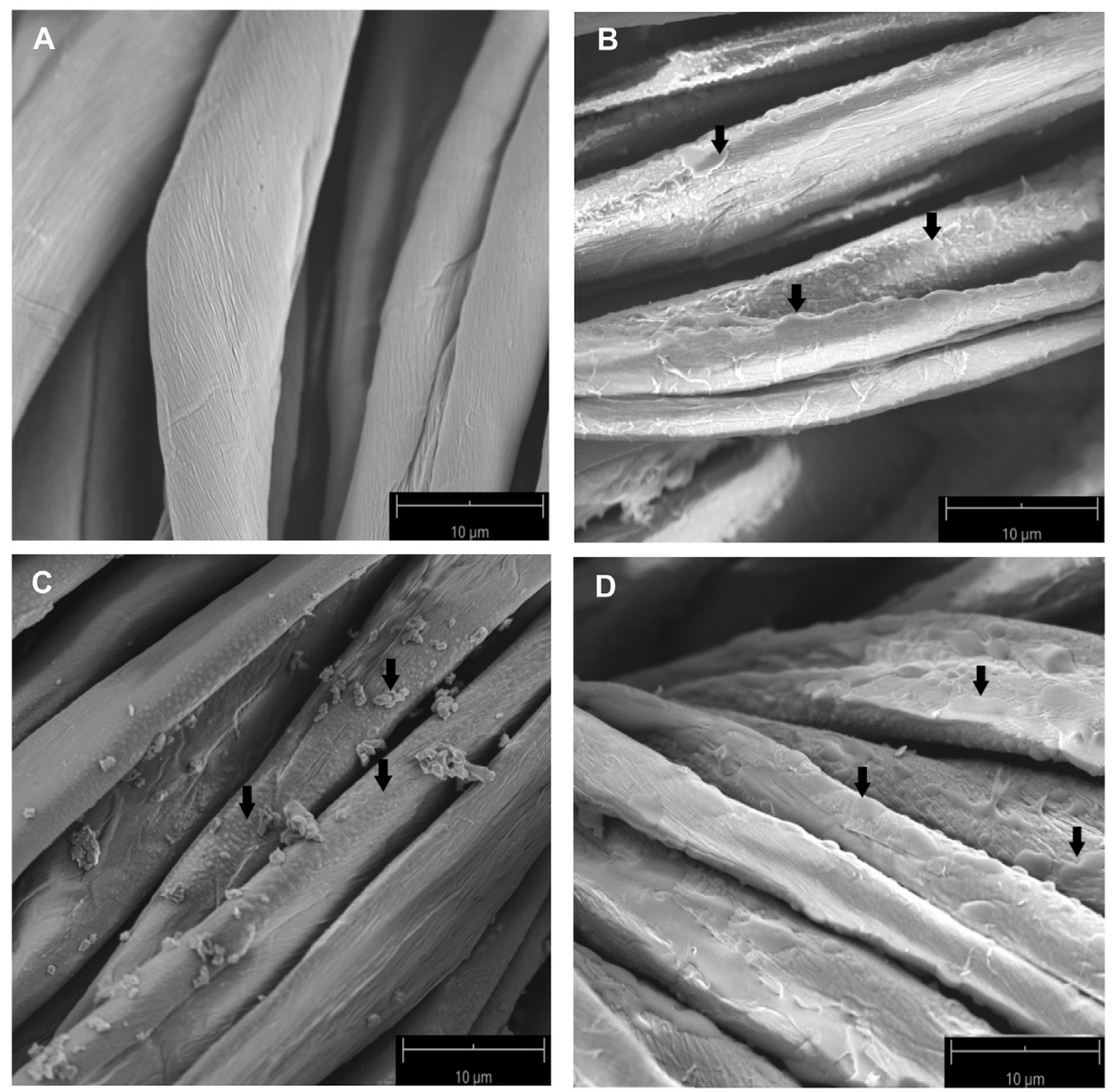

Fig. 9. SEM microphotographs of functionalized cotton textiles (magnification: $5600 \times$ ); A) control (washed cotton textile); B) zein particles without ellagic acid; C) zein particles with ellagic acid (35\%EtOH) and D) zein particles with ellagic acid (40\%EtOH).

acid from the zein particles.

The antibacterial effect of the cotton fabrics functionalized with the zein particles, with and without ellagic acid, observed for $E$. coli was similar to the effect described for other antimicrobial textiles developed [55-61]. However, for $S$. aureus the antibacterial effect presented by the textiles was lower when compared to the values reported in other works [62].

\subsection{Washing and friction fastness of functionalized cotton textiles}

Any coating made on the surface of textiles to be commercially accepted, must present an acceptable fastness to washing and friction. In order to assess the strength of the coating performed (free zein and zein particles), two tests were performed, namely fastness to rubbing and to domestic washing. The results obtained (Table 1) show that the functionalized samples presented high fastness to rubbing and domestic washing (4-5). The application of this protein, in free form or as particles, has the potential to develop hydrophobic and antimicrobial coatings, without compromising the material properties, making zein suitable for an eco-friendly industrial application.
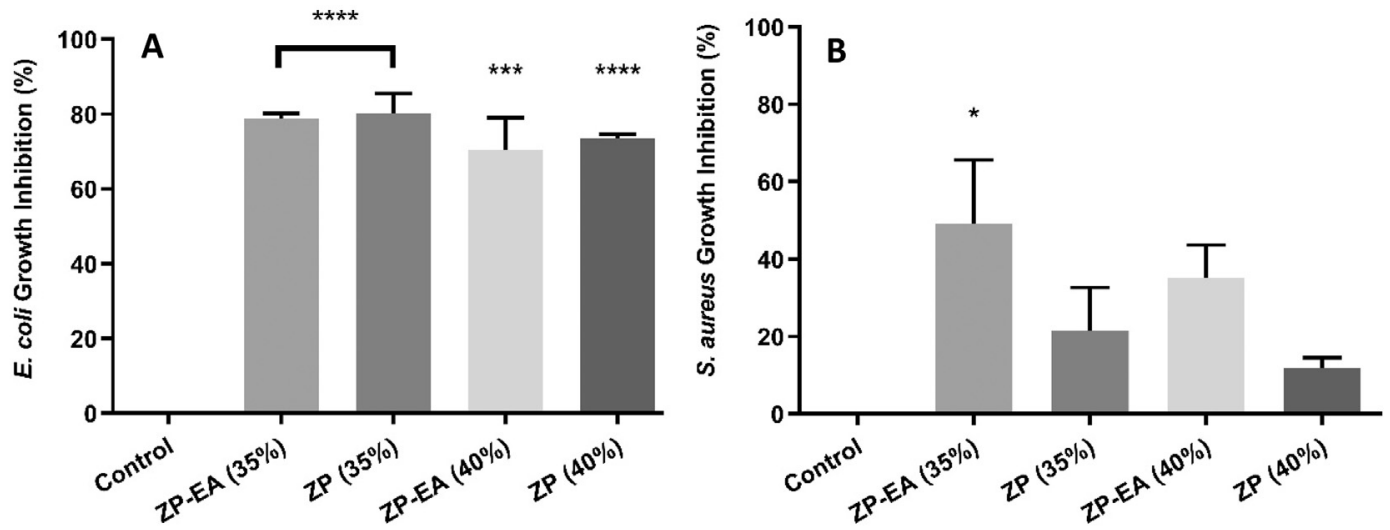

Fig. 10. Antimicrobial activity of functionalized cotton textiles by zein particles (ZP) and zein particles with ellagic acid (ZP-EA) in $35 \%$ and $40 \%$ of ethanol solution in Escherichia coli (A) and Staphylococcus aureus (B). The results were compared to the control cotton sample (***** $=P<.0001 ; * * * * P \leq .001 ; * P \leq .05)$. 
Table 1

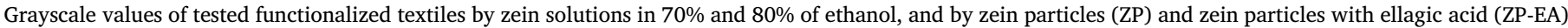
in $35 \%$ and $40 \%$ of ethanol solution, evaluated in terms of rubbing and washing fastness.

\begin{tabular}{|c|c|c|c|c|c|c|c|c|c|}
\hline \multicolumn{8}{|l|}{ Washing fastness } & \multicolumn{2}{|c|}{ Friction fastness } \\
\hline & Colour & Wool & Acrylic & Polyester & Polyamide & Cotton & Acetate & Dry & Wet \\
\hline$[$ zein $]=50 \mathrm{~g} / \mathrm{L}(70 \%$ EtOH $)$ & 5 & 4 & $4 \mid 5$ & $4 \mid 5$ & 4 & 5 & $4 \mid 5$ & 5 & 5 \\
\hline$[$ zein $]=50 \mathrm{~g} / \mathrm{L}(80 \%$ EtOH $)$ & 4 & 4 & $4 \mid 5$ & 5 & $4 \mid 5$ & $4 \mid 5$ & 5 & 5 & 5 \\
\hline $\mathrm{ZP}(35 \% \mathrm{EtOH})$ & 5 & 4 & 5 & 5 & 4 & 5 & 5 & 5 & 5 \\
\hline $\mathrm{ZP}+\mathrm{EA}(35 \% \mathrm{EtOH})$ & 5 & 4 & 5 & 5 & $4 \mid 5$ & 5 & 5 & 5 & 5 \\
\hline $\mathrm{ZP}(40 \% \mathrm{EtOH})$ & $4 \mid 5$ & 4 & $4 \mid 5$ & 4 & 4 & $4 \mid 5$ & 5 & 5 & 5 \\
\hline $\mathrm{ZP}+\mathrm{EA}(40 \% \mathrm{EtOH})$ & 5 & 4 & $4 \mid 5$ & $4 \mid 5$ & 4 & $4 \mid 5$ & $4 \mid 5$ & 5 & $4 \mid 5$ \\
\hline
\end{tabular}

Table 2

Air Permeability of tested functionalized textiles by zein solutions in $70 \%$ and $80 \%$ of ethanol, and by zein particles (ZP) and zein particles with ellagic acid (ZP-EA) in $35 \%$ and $40 \%$ of ethanol solution.

Air Permeability $\left(1 / \mathrm{m}^{2} / \mathrm{s}\right)$

\begin{tabular}{ll}
\hline Control (non coated) & $2342 \pm 95,89$ \\
[zein] $=50 \mathrm{~g} / \mathrm{L} ;(70 \%$ EtOH) & $2298 \pm 93,79$ \\
[zein] $=50 \mathrm{~g} / \mathrm{L} ;(70 \%$ EtOH $)$ & $2141 \pm 98,03$ \\
ZP $(35 \%$ EtOH) & $2262 \pm 70,36$ \\
ZP + EA (35\%EtOH) & $2298 \pm 62,68$ \\
ZP $(40 \%$ EtOH) & $2161 \pm 84,26$ \\
ZP + EA (40\%EtOH) & $2187 \pm 40,29$
\end{tabular}

\subsection{Air permeability of functionalized cotton textiles}

Air permeability is usually defined as the amount of air flow passed through a specific area of a textile. Since this parameter greatly influences the thermal comfort properties of a textile, the ability to be permeable to the air might affect the wearability of a given textile product [63]. The effect of zein coatings, in the free form or as particles, on the air permeability of the functionalized cotton textiles was evaluated (Table 2). The results obtained show that the functionalized textiles present lower air permeability than the non-functionalized cotton (control). Despite the lower permeability presented by the functionalized textiles, the decrease was not significant, with percentages of reduction between $2 \%$ and $9 \%$. The decrease observed is not considered sufficient to disturb or reduce the wearability of a final product produced using these textiles. The lower air permeability of the functionalized textiles also confirmed the presence of the zein at the cotton textile surfaces.

\section{Conclusions}

We successfully developed hydrophobic and antimicrobial cotton textiles by coating with zein applied in the free form or as particles encapsulating the antimicrobial compound, ellagic acid. The highest hydrophobicity was achieved when coating the cotton textiles with $50 \mathrm{~g} / \mathrm{L}$ zein prepared in $70 \%$ ethanol. The samples coated in these conditions presented contact angles equal or greater than $90^{\circ}$ and improved mechanical properties.

The controlled release of ellagic acid from textiles coated with zein particles was tested against different mimetic biologic solutions. The release profile was dependent on the ethanol concentration used during particles preparation, on the sweat solution $\mathrm{pH}$ and on the external media used during dialysis (water $v s$ micellar solution).

The textiles coated with zein particles containing ellagic acid revealed antimicrobial activity against $E$. coli and $S$. aureus. For the Gramnegative bacteria, $E$. coli, the inhibitory action was related with the action of zein protein, whereas for the Gram positive, $S$. aureus, there was a combined effect of both protein and ellagic acid. The findings support the application of zein for the development of functionalized textiles for high-added value specialized textiles.

\section{Declaration of Competing Interest}

The authors declare that they have no known competing financial interests or personal relationships that could have appeared to influence the work reported in this paper.

\section{Acknowledgements}

This study was supported by the Portuguese Foundation for Science and Technology (FCT) under the scope of the strategic funding of UIDB/ 04469/2020 unit and BioTecNorte operation (NORTE-01-0145-FEDER000004) funded by European Regional Development Fund under the scope of Norte2020 - Programa Operacional Regional do Norte. The authors also thanks to FCT for funding: Jennifer Noro (SFRH/BD/ 121673/2016),Filipa Gonçalves (SFRH/BD/114684/2016) and Carla Silva (SFRH/IF/00186/2015).

\section{Appendix A. Supplementary data}

Supplementary data to this article can be found online at https:// doi.org/10.1016/j.reactfunctpolym.2020.104664.

\section{References}

[1] P.J. Rivero, A. Urrutia, J. Goicoechea, F.J. Arregui, Nanomaterials for functional textiles and fibers, Nanoscale Res. Lett. 10 (1) (2015) 501, , https://doi.org/10. 1186/s11671-015-1195-6.

[2] V. Lorscheiter, L.F. Folle, A eficácia de produtos hidrofóbicos aplicados em tecidos 90\% poliéster 10\% elastano estampados, Matéria (Rio Janeiro) 22 (3) (Aug. 2017), https://doi.org/10.1590/s1517-707620170003.0203.

[3] B. Cortese, D. Caschera, G. Padeletti, G.M. Ingo, G. Gigli, A brief review of surfacefunctionalized cotton fabrics, Surf. Innov. 1 (3) (2013) 140-156, https://doi.org/ 10.1680/si.13.00008.

[4] J. Cruz, R. Fangueiro, Surface modification of natural fibers: a review, Proc. Eng. 155 (2016) 285-288, https://doi.org/10.1016/j.proeng.2016.08.030.

[5] M. Messaoud, M. Houmard, S. Briche, F. Roussel, M. Langlet, Hydrophobic functionalization of cotton-based textile fabrics through a non-fluorinated sol-gel route, J. Sol-Gel Sci. Technol. 55 (Aug. 2010) 243-254, https://doi.org/10.1007/s10971010-2240-7.

[6] S. Park, J. Kim, C.H. Park, Superhydrophobic textiles : review of theoretical definitions, fabrication and functional evaluation, J. Eng. Fiber. Fabr. 10 (4) (2015).

[7] N. Forsman, A. Lozhechnikova, A. Khakalo, L.-S. Johansson, J. Vartiainen, M. Österberg, Layer-by-layer assembled hydrophobic coatings for cellulose nanofibril films and textiles, made of polylysine and natural wax particles, Carbohydr. Polym. 173 (2017) 392-402, https://doi.org/10.1016/j.carbpol.2017.06.007.

[8] J. Jeevahan, M. Chandrasekaran, G. Britto Joseph, R.B. Durairaj, G. Mageshwaran, Superhydrophobic surfaces: a review on fundamentals, applications, and challenges, J. Coat. Technol. Res. 15 (2) (2018) 231-250, https://doi.org/10.1007/ s11998-017-0011-x.

[9] E.J. Falde, S.T. Yohe, Y.L. Colson, M.W. Grinstaff, Superhydrophobic materials for biomedical applications, Biomaterials 104 (Oct. 2016) 87-103, https://doi.org/10. 1016/j.biomaterials.2016.06.050.

[10] W. Ding, Z. Cao, B. Wang, S. Xu, Z. Wang, Research on hydrophobic properties of grating structure on Monocrystalline silicon fabricated using micromachining, Adv. Mater. Sci. Eng. 2019 (2019) 3706750, https://doi.org/10.1155/2019/3706750.

[11] G. Wen, Z. Guo, W. Liu, Biomimetic polymeric superhydrophobic surfaces and nanostructures: from fabrication to applications, Nanoscale 9 (10) (2017) 3338-3366, https://doi.org/10.1039/C7NR00096K.

[12] B. Gutarowska, A.M.E.-H.-Y. Jeon (Ed.), Microbial Degradation of Woven Fabrics and Protection Against Biodegradation, IntechOpen, Rijeka, 2012(p. Ch. 10).

[13] D.S. Morais, R.M. Guedes, M.A. Lopes, Antimicrobial Approaches for Textiles : From 
Research to Market, (2016), pp. 1-21, https://doi.org/10.3390/ma9060498.

[14] G. Soares, A. Magalhães, A. Vasconcelos, J. Santos, Comfort and antimicrobial propertes of developed bamboo, polyester and cotton knitted spacer fabrics, Cellul. Chem. Technol. 52 (2018) 113-121.

[15] A. Hebeish, et al., Green synthesis of easy care and antimicrobial cotton fabrics, Carbohydr. Polym. 86 (4) (2011) 1684-1691, https://doi.org/10.1016/j.carbpol. 2011.06.086.

[16] U. Shimanovich, A. Cavaco-Paulo, Y. Nitzan, A. Gedanken, Sonochemical coating of cotton and polyester fabrics with 'antibacterial' BSA and casein spheres, Chem. A Eur. J. 18 (1) (2012) 365-369, https://doi.org/10.1002/chem.201100781.

[17] Y.S. Joung, C.R. Buie, Antiwetting fabric produced by a combination of layer-bylayer assembly and electrophoretic deposition of hydrophobic nanoparticles, ACS Appl. Mater. Interfaces 7 (36) (Sep. 2015) 20100-20110, https://doi.org/10.1021/ acsami.5b05233.

[18] W. Ismail, Sol-gel technology for innovative fabric finishing-a review, J. Sol-Gel Sci. Technol. 78 (Mar. 2016), https://doi.org/10.1007/s10971-016-4027-y.

[19] M. Shabbir, F. Mohammad, Natural polymers: scope in textile functionalization, Natural Polymers: Derivatives, Blends and Composites, vol. I, 2016, pp. 157-170.

[20] R. Vielnascher, et al., Smart textiles in wound care : functionalization of cotton PET blends with antimicrobial, J. Mater. Chem. B 7 (42) (2019) 6592-6603, https://doi.org/10.1039/c9tb01474h.

[21] J. Boateng, O. Catanzano, Silver and silver nanoparticle-based antimicrobial dres sings, Ther. Dressings Wound Heal. Appl. 1 (2020) 157-184.

[22] J. Liu, F.O. Dunne, X. Fan, X. Fu, W.-H. Zhong, A protein-functionalized microfiber/ protein nanofiber bi-layered air filter with synergistically enhanced filtration performance by a viable method, Sep. Purif. Technol. 229 (2019) 115837, https://doi. org $/ 10.1016 / j$.seppur.2019.115837.

[23] Z. Liu, X. Cao, S. Ren, J. Wang, H. Zhang, Physicochemical characterization of a zein prepared using a novel aqueous extraction technology and tensile properties of the zein film, Ind. Crop. Prod. 130 (Apr. 2019) 57-62, https://doi.org/10.1016/J. INDCROP.2018.12.071.

[24] C. Sun, L. Dai, X. He, F. Liu, F. Yuan, Y. Gao, Effect of heat treatment on physical, structural, thermal and morphological characteristics of zein in ethanol-water solution, Food Hydrocoll. 58 (2016) 11-19, https://doi.org/10.1016/j.foodhyd.2016. 02.014 .

[25] M.R. Kasaai, Zein and zein -based nano-materials for food and nutrition applications: a review, Trends Food Sci. Technol. 79 (2018) 184-197, https://doi.org/10. 1016/j.tifs.2018.07.015.

[26] M. Demir, L. Ramos-Rivera, R. Silva, S.N. Nazhat, A.R. Boccaccini, Zein-based composites in biomedical applications, J. Biomed. Mater. Res. Part A 105 (6) (Jun. 2017) 1656-1665, https://doi.org/10.1002/jbm.a.36040.

[27] C.-H. Xue, S.-T. Jia, J. Zhang, L.-Q. Tian, H.-Z. Chen, M. Wang, Preparation of superhydrophobic surfaces on cotton textiles, Sci. Technol. Adv. Mater. 9 (3) (2008) 35008, https://doi.org/10.1088/1468-6996/9/3/035008.

[28] S. Kim, J. Xu, Aggregate formation of zein and its structural inversion in aqueous ethanol, J. Cereal Sci. 47 (1) (2008) 1-5, https://doi.org/10.1016/j.jcs.2007.08. 004.

[29] M. Pascoli, R. de Lima, L.F. Fraceto, Zein nanoparticles and strategies to improve colloidal stability: a mini-review, Front. Chem. 6 (2018) 6, https://doi.org/10. 3389/fchem.2018.00006.

[30] F. Dong, G.W. Padua, Y. Wang, Controlled formation of hydrophobic surfaces by self-assembly of an amphiphilic natural protein from aqueous solutions, Soft Matter 9 (25) (2013) 5933-5941, https://doi.org/10.1039/C3SM50667C.

[31] R. Paliwal, S. Palakurthi, Zein in controlled drug delivery and tissue engineering, J. Control. Release 189 (Sep. 2014) 108-122, https://doi.org/10.1016/J.JCONREL. 2014.06.036.

[32] E. Corradini, P.S. Curti, A.B. Meniqueti, A.F. Martins, A.F. Rubira, E.C. Muniz, Recent advances in food-packing, pharmaceutical and biomedical applications of zein and zein-based materials, Int. J. Mol. Sci. 15 (12) (2014) 22438-22470, https://doi.org/10.3390/ijms151222438.

[33] N. Said, N. Sarbon, Protein-based active film as antimicrobial food packaging: a review, Active Antimicrobial Food Packaging, 2019.

[34] C. Yao, L. Xinsong, T. Song, Electrospinning and crossfinking of Zein nanofiber mats, J. Appl. Polym. Sci. 103 (Jan. 2007) 380-385, https://doi.org/10.1002/app. 24619.

[35] C.M. Güçbilmez, A. Yemenicioğlu, A. Arslanoğlu, Antimicrobial and antioxidant activity of edible zein films incorporated with lysozyme, albumin proteins and disodium EDTA, Food Res. Int. 40 (1) (2007) 80-91, https://doi.org/10.1016/j. foodres.2006.08.007.

[36] T. Bilenler, I. Gokbulut, K. Sislioglu, I. Karabulut, Antioxidant and antimicrobial properties of thyme essential oil encapsulated in zein particles, Flavour Fragr. J. 30 (5) (2015) 392-398, https://doi.org/10.1002/ffj.3254.

[37] K.K. Ghudhaib, E.R. Hanna, A.H. Jawad, Effect of ellagic acid on some types of pathogenic bacteria, J. Al-Nahrain Univ. Sci. 13 (2) (2010) 79-85, https://doi.org/ 10.22401/jnus.13.2.09.

[38] B. Thiem, O. Goślińska, Antimicrobial activity of Rubus chamaemorus leaves, Fitoterapia 75 (1) (2004) 93-95, https://doi.org/10.1016/j.fitote.2003.08.014.

[39] R. Förch, H. Schönherr, A. Tobias, A. Jenkins, Surface design: applications in bioscience and nanotechnology, Mater. Today 12 (7) (2009) 2009, https://doi.org/ 10.1016/S1369-7021(09)70210-X.

[40] G. Chen, S. Dong, S. Zhao, S. Li, Y. Chen, Improving functional properties of zein film via compositing with chitosan and cold plasma treatment, Ind. Crop. Prod. 129 (29) (2019) 318-326, https://doi.org/10.1016/j.indcrop.2018.11.072.

[41] Y. Miao, R. Yang, D. Deng, L.-M. Zhang, Poly(L-lysine) modified zein nanofibrous membranes as efficient scaffold for adhesion, proliferation, and differentiation of neural stem cells, RSC Adv. 7 (Mar. 2017) 17711-17719, https://doi.org/10.1039/ C7RA00189D.

[42] E. Portella, D. Romanzini, C. Angrizani, S. Amico, A. Zattera, Influence of stacking sequence on the mechanical and dynamic mechanical properties of cotton/glass fiber reinforced polyester composites, Mater. Res. 19 (Jun. 2016), https://doi.org/ 10.1590/1980-5373-MR-2016-0058.

[43] D. Usoltsev, V. Sitnikova, A. Kajava, M. Uspenskaya, Systematic FTIR spectroscopy study of the secondary structure changes in human serum albumin under various denaturation conditions, Biomolecules 9 (8) (2019) 1-17, https://doi.org/10.3390/ biom9080359.

[44] H. Özdemir, E. Mert, The effects of fabric structural parameters on the tensile, bursting, and impact strengths of cellular woven fabrics, J. Text. Inst. 104 (3) (2013) 330-338, https://doi.org/10.1080/00405000.2012.725521.

[45] T. Luxbacher, T. Pušić, H. Bukšek, I. Petrinic, The Zeta Potential of Textile Fabrics: A Review, (2016).

[46] J. Fluhr, P. Elias, Fluhr JW, Elias PMStratum corneum pH: formation and function of the 'acid mantle', Exogen Dermatol. 1 (Nov. 2002) 163-175.

[47] T. Costa, et al., Polymeric electrospun fibrous dressings for topical co-delivery of acyclovir and Omega-3 fatty acids, Front. Bioeng. Biotechnol. 7 (2019) 390, https://doi.org/10.3389/fbioe.2019.00390.

[48] V. Cabra, R. Arreguin, R. Vazquez-Duhalt, A. Farres, Effect of temperature and $\mathrm{pH}$ on the secondary structure and processes of oligomerization of $19 \mathrm{kDa}$ alpha-zein, Biochim. Biophys. Acta Proteins Proteomics 1764 (6) (2006) 1110-1118, https:// doi.org/10.1016/j.bbapap.2006.04.002.

[49] J. Bouman, P. Belton, P. Venema, E. van der Linden, R. de Vries, S. Qi, Controlled release from Zein matrices: interplay of drug hydrophobicity and $\mathrm{pH}$, Pharm. Res. 33 (3) (2016) 673-685, https://doi.org/10.1007/s11095-015-1818-8.

[50] E.E. Moros, D. Darnoko, M. Cheryan, E.G. Perkins, J. Jerrell, Analysis of Xanthophylls in corn by HPLC, J. Agric. Food Chem. 50 (21) (Oct. 2002) 5787-5790, https://doi.org/10.1021/jf0201091.

[51] S.J. Sampathkumar, P. Srivastava, S. Ramachandran, K. Sivashanmugam, K.M. Gothandam, Lutein: a potential antibiofilm and antiquorum sensing molecule from green microalga Chlorella pyrenoidosa, Microb. Pathog. 135 (2019) 103658, https://doi.org/10.1016/j.micpath.2019.103658.

[52] P.S. Bernstein, et al., Lutein, zeaxanthin, and meso-zeaxanthin: the basic and clinical science underlying carotenoid-based nutritional interventions against ocular disease, Prog. Retin. Eye Res. 50 (Jan. 2016) 34-66, https://doi.org/10.1016/j. preteyeres.2015.10.003

[53] R. De, et al., Antimicrobial activity of ellagic acid against helicobacter pylori isolates from India and during infections in mice, J. Antimicrob. Chemother. 73 (6) (Mar. 2018) 1595-1603, https://doi.org/10.1093/jac/dky079.

[54] D. Zhou, Z.H. Liu, D.M. Wang, D.W. Li, L.N. Yang, W. Wang, Chemical composition, antibacterial activity and related mechanism of valonia and shell from Quercus variabilis Blume (Fagaceae) against Salmonella paratyphi a and Staphylococcus aureus, BMC Complement. Altern. Med. 19 (1) (2019) 1-12, https://doi.org/10 1186/s12906-019-2690-6.

[55] X. Song, U. Cvelbar, P. Strazar, L. Vossebein, A. Zille, Antimicrobial efficiency and surface interactions of quaternary ammonium compound absorbed on dielectric barrier discharge (DBD) plasma treated Fiber-based wiping materials, ACS Appl. Mater. Interfaces 12 (1) (Jan. 2020) 298-311, https://doi.org/10.1021/acsami. 9b18746.

[56] Z. Li, J. Chen, W. Cao, D. Wei, A. Zheng, Y. Guan, Permanent antimicrobial cotton fabrics obtained by surface treatment with modified guanidine, Carbohydr. Polym. 180 (2018) 192-199, https://doi.org/10.1016/j.carbpol.2017.09.080.

[57] J. Ran, et al., Immobilizing CuO/BiVO4 nanocomposite on PDA-templated cotton fabric for visible light photocatalysis, antimicrobial activity and UV protection, Appl. Surf. Sci. 493 (2019) 1167-1176, https://doi.org/10.1016/j.apsusc.2019.07. 137.

[58] J. Chen, et al., Dual antimicrobial actions on modified fabric leads to inactivation of drug-resistant bacteria, Dye Pigment. 140 (2017) 236-243, https://doi.org/10. 1016/j.dyepig.2017.01.032.

[59] M. Maghimaa, S.A. Alharbi, Green synthesis of silver nanoparticles from Curcuma longa L. and coating on the cotton fabrics for antimicrobial applications and wound healing activity, J. Photochem. Photobiol. B Biol. 204 (2020) 111806, https://doi. org/10.1016/j.jphotobiol.2020.111806.

[60] E.S. Abdel-Halim, S.S. Al-Deyab, A.Y.A. Alfaifi, Cotton fabric finished with $\beta$-cyclodextrin: inclusion ability toward antimicrobial agent, Carbohydr. Polym. 102 (2014) 550-556, https://doi.org/10.1016/j.carbpol.2013.11.074.

[61] F. Fang, et al., Environmentally friendly assembly multilayer coating for flame retardant and antimicrobial cotton fabric, Prog. Org. Coatings 90 (2016) 258-266, https://doi.org/10.1016/j.porgcoat.2015.09.025.

[62] M. Coradi, et al., Production of antimicrobial textiles by cotton fabric functionalization and pectinolytic enzyme immobilization, Mater. Chem. Phys. 208 (Apr. 2018) 28-34, https://doi.org/10.1016/J.MATCHEMPHYS.2018.01.019.

[63] R. Mishra, J. Militky, M. Venkataraman, Nanoporous materials, in: R. Mishra, J.B.T.-N.T. Militky (Eds.), The Textile Institute Book Series, Woodhead Publishing, 2019, pp. 311-353. 